\title{
Effect of ultrasonic impact time on Microstructure and properties of 7A52 aluminum alloy tandem MIG welded joint
}

\section{Furong Chen}

Inner Mongolia University of Science and Technology

Yihang Yang ( $\triangle$ yangyihang0826@163.com )

Inner Mongolia University of Science and Technology https://orcid.org/0000-0001-8904-5616

Nan Li

Inner Mongolia University of Science and Technology

\section{Research Article}

Keywords: 7A52 aluminum alloy, tandem MIG, UIT, fatigue strength

Posted Date: March 16th, 2021

DOl: https://doi.org/10.21203/rs.3.rs-313541/v1

License: (c) (i) This work is licensed under a Creative Commons Attribution 4.0 International License.

Read Full License

Version of Record: A version of this preprint was published at The International Journal of Advanced Manufacturing Technology on July 7th, 2021. See the published version at https://doi.org/10.1007/s00170-021-07599-x. 


\section{Abstract}

7A52 (Al-Zn-Mg-Cu) alloy is a high-strength aluminum alloy, its welded joints are often accompanied by defects such as poor wear resistance and low fatigue strength. Herein, we try to optimize the welded joint of 7A52 aluminum alloy by using ultrasonic impact treatment (UIT). Generally, the mechanical properties such as microhardness and fatigue strength of the welded joint after UIT will be improved. 7A52 aluminum alloy tandem metal inert gas (MIG) welded joints with UIT time per unit area of $2.5 \mathrm{~min}, 5 \mathrm{~min}$, $10 \mathrm{~min}, 15 \mathrm{~min}, 30 \mathrm{~min}$, and $75 \mathrm{~min}$ were studied. Through the surface topography, microstructure observation, and mechanical properties test, the time parameters of excessive treatment, lack of treatment, and proper treatment were selected, and the effects of UIT, excessive treatment, lack of treatment, and proper treatment on fatigue strength were analyzed. Test results show that, the mechanical properties of welded joints after UIT are improved. The proper treatment time is $15 \mathrm{~min}$ and its fatigue strength is $37.86 \mathrm{MPa}$, respectively under the stress ratio of 0.1 . Compared to the original welding condition with a fatigue strength of $28.61 \mathrm{MPa}$, the fatigue strength of the welded joints of 7A52 aluminum alloy increased by $32.33 \%$. The largest percentage of grain size reduction occurs when the UIT is 15 min. Moreover, excessive treatment and lack of treatment will not further refine the grains and optimize the mechanical properties.

\section{Introduction}

As a lightweight metal, aluminum alloy has met the needs of aircraft and sophisticated equipment at different times. Lightweight is the eternal goal pursued in aerospace. With the continuous innovation of aircraft design ideas, advanced aircraft component manufacturing has put high requirements on materials and thus, demand on greater performance of aluminum alloy is also increasing [1]. 7A52 (Al-Zn$\mathrm{Mg}-\mathrm{Cu}$ ) aluminum alloy is a high-strength aluminum alloy produced in China, which is widely used in aerospace and other departments. However, when welded 7A52 aluminum alloy exhibits welding cracks, welding porosity, and low weld strength. The welded joint has poor wear resistance and low fatigue strength $[2,3]$. Therefore, improving the fatigue properties of 7A52 armored aluminum alloy has become an urgent problem to be solved in popularizing its practical application in welded components engineering.

As a new welding technology to achieve high efficiency, tandem metal inert gas (MIG) welding has the advantages of good mechanical properties of joints and high welding efficiency [4]. Moreover, tandem MIG welding can effectively reduce the probability of occurrence of welding pore defects, refine the grain of the weld zone, and obtain high-quality fish scale weld [5]. Hence, tandem MIG welding is more suitable for the welding of 7A52 aluminum alloy thick plate. However, due to the mutual interference of the electromagnetic field between the two arcs during tandem MIG welding, some problems arise such as poor welding stability and poor fatigue performance.

Ultrasonic impact treatment (UIT) is used to impact the surface of the metal component with high frequency, which makes the surface of the impacted components produce large compressive plastic 
deformation [6]. It can effectively eliminate the residual tensile stress on the surface of welded joint and weld zone, and achieve the effect of reducing the residual stress in welded parts [7,8]. After UIT, the wear and fatigue properties of tandem MIG welding can be effectively improved. At present, only a simple attempt has been made related to this research. Although the properties of welded joints have been improved, excessive impact will lead to the failure of metallurgical combinations between the strong plastic deformation layer and the undeformed layer, generating superimposed defects, resulting in a new stress concentration area, leading to fatigue cracking [9]. In engineering practice, we still don't know how to deal with improper handlings such as excessive treatment and lack of treatment. The UIT of tandem MIG welded aluminum alloy specimens was carried out at different times and lengths, so as to obtain better UIT process. This will lay a theoretical and experimental foundation for the wide application of tandem MIG welded joint of 7A52 aluminum alloy in the future.

\section{Experimental}

The material used in this investigation is 7A52 (Al-Zn-Mg-Cu) aluminum alloy with the chemical composition and mechanical properties of the wire and substrate are represented in Tab. 1 and Tab. 2 respectively. Aluminum-magnesium (Al-Mg) ER5356 alloy welding wire with a size of $1.6 \mathrm{~mm}$ was selected in the experiment.

Tab. 1 Chemical composition of 7A52 alloy and ER5356 welding wire (mass fraction, \%).

\begin{tabular}{|llllllllll|}
\hline Alloys & $\mathrm{Mg}$ & $\mathrm{Cr}$ & $\mathrm{Si}$ & $\mathrm{Fe}$ & $\mathrm{Cu}$ & $\mathrm{Zn}$ & $\mathrm{Mn}$ & $\mathrm{Ti}$ & $\mathrm{Al}$ \\
\hline 7A52 & 2.26 & 0.23 & 0.24 & 0.3 & 0.13 & 4.21 & 0.31 & - & balance \\
ER5356 & $<5.5$ & $<0.2$ & 0.25 & 0.4 & 0.1 & 0.05 & $<0.2$ & $<0.2$ & balance \\
\hline
\end{tabular}

Tab. 2 Mechanical properties of base material 7A52.

\begin{tabular}{|lll|}
\hline Tensile strength, (MPa) & Yield strength, (MPa) & Elongation (\%) \\
\hline 532.8 & 483.3 & 11.43 \\
\hline
\end{tabular}

Welding was carried out using the digital pulse tandem MIG welding machine Fronius TPS5000 and the matching welding robot. Fig. 1 shows the tandem MIG welding process during welding, multi-layer and multi-pass welding are adopted. The groove form of welding is butt V-groove with a groove gap of $2 \mathrm{~mm}$ between two plates and a groove angle of 30 on one side. After welding, the appearance with fish scale pattern is formed and no obvious splash, undercut, and other defects were observed. Tab. 3 lists the welding parameters of tandem MIG welding.

UIT-125 ultrasonic impact equipment was used to treat 7A52 aluminum alloy welded joint with the UIT process shown in Fig. 1. The impact degree is characterized by the ultrasonic impact time per unit area $(10 \mathrm{~mm} \times 10 \mathrm{~mm})$. The following parameters are all expressed by ultrasonic impact time, which are 0 min, 
$2.5 \mathrm{~min}, 5 \mathrm{~min}, 10 \mathrm{~min}, 15 \mathrm{~min}, 30 \mathrm{~min}$, and $75 \mathrm{~min}$. Ultrasonic impact process parameters are shown in Tab. 4.

Tab. 3 Welding parameters of 7A52 aluminum alloy tandem MIG welding

\begin{tabular}{|lll|}
\hline Parameter & Main & Sub \\
\hline Welding Current I/A & 190 & 235 \\
\hline Arc Voltage U/V & 24 & 24 \\
\hline Welding Speed $\mathrm{v}_{1} /\left(\mathrm{cm} \cdot \mathrm{min}^{-1}\right)$ & 50 & 50 \\
\hline Feeding Speed $\mathrm{v}_{2} /\left(\mathrm{cm} \cdot \mathrm{min}^{-1}\right)$ & 10 & 10 \\
\hline Mass Fraction of Protective Gas $\rrbracket$ & 99.9 & 99.9 \\
\hline
\end{tabular}

In this experiment, the surface morphology of the joint after UIT at different times was observed using FEI-QUANTA 650 scanning electron microscope, and the longitudinal section morphology after UIT treatment was observed by metallographic optical microscop. HXD-1000TM digital microhardness was used to measure the microhardness of the welded joint along the depth direction in different times of ultrasonic treatment. The X-ray stress analyzer of X-stress3000 measured the residual stress distribution of the welded joint at a different time of UIT, and the grain size of the joint surface after UIT was analyzed and calculated. The high frequency fatigue testing machine controlled by MTS Landmark was used for the fatigue test with a stress cycle ratio of $\mathrm{R}=0.1$ and a loading frequency of $121 \mathrm{~Hz}-137 \mathrm{~Hz}$. The specimens were cut by wire cut electrical discharge machining (WEDM), and the fatigue specimen size of the welded joint is shown in Fig. 2. The sample was placed on the fatigue testing machine for multiple alternating loads, and the fatigue strength of the sample was measured. Relevant studies shown that, UIT has no significant effect on the tensile strength of the welded joint[10]. Therefore, only fatigue strength tests were carried out.

Tab. 4. Welding parameters of 7A52 aluminum alloy tandem MIG welding

\begin{tabular}{|llll|}
\hline $\begin{array}{l}\text { Working frequency } \\
\mathrm{f} / \mathrm{kHz}\end{array}$ & $\begin{array}{l}\text { Working current } \\
\text { I/A }\end{array}$ & $\begin{array}{l}\text { Impulse needle diameter } \\
\mathrm{d} / \mathrm{mm}\end{array}$ & $\begin{array}{l}\text { Number of impact } \\
\text { needles }\end{array}$ \\
\hline 30 & 2.26 & 4 & 7 \\
\hline
\end{tabular}

\section{Results}

\subsection{Surface Morphology Analysis}

The Surface morphology of 7A52 aluminum alloy tandem MIG welded joint with different UIT time were shown in Fig. 3. Fig. 3a shows the surface morphology without UIT, while Fig. 3b shows the surface 
morphology after UIT for $2.5 \mathrm{~min}$. It can be seen that the surface before UIT is not flat and there are many interlaced, disordered, narrow, and deep strip gullies. After UIT, the morphology with sharp and fine gullies disappeared, and became flat as a whole with some of them being obviously uneven and small holes were distributed. The surface morphologies with UIT time of $5 \mathrm{~min}$ and $10 \mathrm{~min}$ shown in Fig. $3 \mathrm{c}$ and $3 \mathrm{~d}$, respectively are basically similar as Fig. $3 \mathrm{~b}$. However, the flat area gradually expands and the holes decrease, showing a better trend of change. Surface morphology of UIT after 15 mins in Fig. 3e reveals the smoothest surface without obvious gullies, implying a better morphology. Fig. $3 \mathrm{f}$ and $3 \mathrm{~g}$ show the surface morphology of UIT time of $30 \mathrm{~min}$ and $75 \mathrm{mins}$, respectively. When UIT is $30 \mathrm{~min}$, the surface begins to become uneven with laminated defects. When the ultrasonic impact time is $75 \mathrm{~min}$, obvious surface peaks and valleys are observed and cracks with a width of about $20 \mu \mathrm{m}$ (with the longest of about $800 \mu \mathrm{m}$ ) appear, which expand to all sides, indicating a poor surface morphology.

\subsection{Surface Roughness Analysis}

The laser confocal microscope was used to measure the samples with different time of UIT for 5 times, and the average value of 5 times was taken (see Fig. 4).

With the increase of ultrasonic impact time, the roughness decreases first and then increases as shown in Fig. 4. The roughness of the original weldment significantly reduces from $44.45 \mu \mathrm{m}$ to $40.94 \mu \mathrm{m}, 37.08 \mu \mathrm{m}$, and $31.63 \mu \mathrm{m}$ for impact times of $2.5 \mathrm{~min}, 5 \mathrm{~min}$, and $10 \mathrm{~min}$, respectively. The specimens treated for 15 min exhibited the least roughness and the best surface quality. When the ultrasonic impact time is 30 minutes, the surface roughness of the specimen did not reduce further. When the treatment time is 75 min, the roughness value is $45.23 \mu \mathrm{m}$, which is greater than the surface roughness of the specimen without UIT. Moreover, the surface quality deteriorates, which shows that excessive UIT can't further improve the surface quality of the specimen. Compared with the treatment for $30 \mathrm{~min}$, the increase of the roughness value is not significant. This means that after the ultrasonic impact time reaches a certain value, further increase of the treatment time can't significantly increase the roughness value, and the change gradually tends to be gentle.

\subsection{Microstructure Analysis}

The surface structure of 7A52 aluminum alloy tandem MIG welded joint after different UIT at 100 times magnification is shown in Fig. 5. Fig. 5a shows the original weld surface structure. It can be seen that the weld surface structure without UIT is still in an equiaxed crystal form with uniform size. No obvious difference from the matrix structure is observed and the surface is relatively flat with good surface quality. Fig. 5b shows the surface structure of the weld with the ultrasonic impact time of $2.5 \mathrm{~min}$. After the UIT, the surface structure begins to undergo plastic deformation with a deformation layer thickness of about $130 \mu \mathrm{m}$. The surface grains are refined and the grain boundaries are not obviously entangled with each other. Obvious differences with the matrix structure are observed. The surface roughness has slight changes and the surface quality is observed to be better. 
It can be seen that after UIT, the surface structure has obvious plastic deformation with the thickness of about $160 \mu \mathrm{m}, 190 \mu \mathrm{m}$, and $210 \mu \mathrm{m}$, for treatment of $5 \mathrm{~min}, 10 \mathrm{~min}$, and $15 \mathrm{~min}$ as shown in Fig. $5 \mathrm{c}, 5 \mathrm{~d}$, and $5 e$, respectively. The surface grains are obviously refined and the increase of grain boundaries deepens the color of the plastic deformation layer, which is related to the matrix group. With the increase of the distance from the matrix, the grains gradually become large and finally, the structure becomes the same as that of the matrix. The flatness of the surface layer changes slightly and a better surface quality is observed. Fig. $5 \mathrm{f}$ and $5 \mathrm{~g}$ show the surface structure of the weld with the treatment of $30 \mathrm{~min}$ and 75 min with the thickness of the plastic deformation layer of about $230 \mu \mathrm{m}$ and $270 \mu \mathrm{m}$, respectively. This time, the surface plastic deformation degree is severe and a plastic flow trend appears. The local is in the form of a vortex and the appearance of equiaxed crystal disappears completely. The surface structure produces spatter and burr and the surface quality is poor.

\subsection{XRD Analysis}

It can be seen from Fig. 6 that with the increase of ultrasonic impact time, the diffraction peak is widened, which is caused by grain refinement, instrument broadening, and micro-stress interaction. The grain size of the joint surface is calculated according to the Scherrer formula (see Equation (1)).

$$
D=K \lambda(\beta \cos \theta)
$$

The value of constant $K$ is related to the definition of $\beta$. When $\beta$ is a half width height, $K$ is 0.89 , while when $\beta$ is the integral width, $K$ is taken as 1.0. The calculated grain size (D) is shown in Fig. 8.

Fig. 7 shows that after UIT, the grain size of the sample surface is refined to the nanometer level. Moreover, with the increase of UIT time, the surface grain size decreases. Under the same chemical composition, the strength and hardness of the material increase with the decrease of grain size $\mathrm{D}$. When the ultrasonic impact time increased from $2.5 \mathrm{~min}$ to $75 \mathrm{~min}$, the grain size decreased by $2.12 \mathrm{~nm}, 0.7 \mathrm{~nm}$, $1.34 \mathrm{~nm}, 0.25 \mathrm{~nm}$, and $0.14 \mathrm{~nm}$. Therefore, with the increase of UIT time, the grain size is constantly decreasing the degree of reduction becoming less and less obvious, especially after the ultrasonic impact time of 15 minutes. The grain refinement process caused by plastic deformation is controlled by many factors, such as material properties, deformation amount, and deformation rate. The grain size decreases with the increase of deformation amount, but when the deformation amount reaches a certain critical value, the change amount of grain size decreases and tends to saturate [11]. With the development of UIT, dislocations form dislocation wall and dislocation tangle through slip, accumulation, interaction, annihilation, and rearrangement, which hinders further movement of dislocations and makes it difficult for the grain fragmentation to reach the "saturation" state.

\subsection{Microhardness Analysis}


Microhardness data in Fig. 8 reveals that the microhardness of the weld area without UIT has little change and fluctuates from $80 \mathrm{HV}$ to $90 \mathrm{HV}$, with an average value of $82.9 \mathrm{HV}$. In addition, after UIT, the microhardness value of the weld surface increases significantly and decreases gradually with the increase of distance from the ultrasonic impact surface, showing a monotonous downward trend. On the other hand, the microhardness value of the part beyond the deformation layer still continues to increase and finally tends to be gentle in the area greater than $1 \mathrm{~mm}$.

\subsection{Residual Stress Analysis}

In this paper, the X-ray diffraction method is used to determine the residual stress of the original welding state and the specimens at different times of UIT. The measurement results are shown in Fig. 9a and the average residual stress at different times of UIT is shown in Fig. $9 \mathrm{~b}$.

It can be seen from Fig. 9a and Fig. 9b that the residual stress of the as-welded 7A52 aluminum alloy welded joint is mainly tensile stress. The maximum residual tensile stress in the weld area is $166.6 \mathrm{MPa}$ and the average value is $82.6 \mathrm{MPa}$. Compared with the distribution of residual stress in as-welded specimens, it can be found that the welded joints of 7A52 aluminum alloy changed from residual tensile stress to residual compressive stress after UIT. With the increase of the distance from the weld center, the residual compressive stress decreases gradually and the curve shows an upward trend [12]. With the increase of UIT time from $2.5 \mathrm{~min}, 5 \mathrm{~min}, 10 \mathrm{~min}, 15 \mathrm{~min}$, and $30 \mathrm{~min}$ to $75 \mathrm{~min}$, the average value of residual pressure stress is: $-63.8 \mathrm{MPa},-101.8 \mathrm{MPa},-66.1 \mathrm{MPa},-141.9 \mathrm{MPa},-119.8 \mathrm{MPa}$, and $-116.5 \mathrm{MPa}$, respectively. It can be seen that the value generally decreases first and then does not change. When the ultrasonic impact time is $15 \mathrm{~min}$, the maximum residual pressure stress is $141.9 \mathrm{MPa}$. The "saturation" of residual stress with the increase of ultrasonic impact time is due to dislocation packing caused by the dislocation slip and rearrangement after UIT. Different dislocation distribution corresponds to different residual stress distribution, i.e., high dislocation density means a more concentrated stress, which is shown as the transformation of tensile and compressive stress [13]. When the treatment time is too long, the dislocation density increases and the dislocation wall hinders further movement of the dislocation to produce a saturation phenomenon. Therefore, a certain amount of residual compressive stress is introduced into the surface of 7A52 aluminum alloy welded joint after treatment, which effectively improves the fatigue performance of 7A52 aluminum alloy welded joint.

\subsection{Fatigue Strength of Tandem MIG Welded Joints}

The median S-N curve of 7A52 aluminum alloy tandem MIG welded joint at different time of as-welded and UIT is shown in Fig. 10. The fatigue strength results at $2 \times 10^{6}$ cycles are listed in Tab. 5 .

Looking at Fig. 10 and Tab. 5, it is difficult to visually evaluate whether the different times of ultrasonic impact have a significant impact on the fatigue strength due to the small difference of the curves of the processed samples. It is necessary to calculate the characteristic S-N curve equation according to the 
median S-N curve equation to accurately evaluate the fatigue strength of different UIT time. Under a stress ratio of 0.1 and with cycle times of $2 \times 10^{6}$, the fatigue strength of the as-welded specimen of tandem MIG welded joint is only $28.61 \mathrm{MPa}$. However, the fatigue strength of the undertreated joint is $29.56 \mathrm{MPa}$, which is $3.32 \%$ higher than that of the as-welded joint. The fatigue strength of the better treated joint is $37.86 \mathrm{MPa}$, which is 32.33 higher than that of the as-welded joint, and the fatigue strength of the excessive treated joint is $27.78 \mathrm{MPa}$ and decreased by 2.9 compared with that of the as-welded joint. From literature [14], the better treatment can increase the fatigue strength most, while the lack of treatment can improve the fatigue strength.

Tab. 5. Fatigue strength results of welded joints after UIT at different times $(r=0.1)$

\begin{tabular}{|llll|}
\hline Stress ratio & Processing state & $\begin{array}{l}\text { Fatigue strength } \\
\left(2 \times 10^{6}\right) \Delta \sigma / \mathrm{MPa}\end{array}$ & $\begin{array}{l}\text { Increase rate } \\
\text { (relative welded state) \% }\end{array}$ \\
\hline 0.1 & Welding state & 28.61 & -- \\
\cline { 2 - 4 } & UIT2.5 & 29.56 & 3.32 \\
\hline UIT15 & 37.86 & 32.33 \\
\hline UIT30 & 27.78 & -2.9 \\
\hline
\end{tabular}

On the other hand, the excessive treatment has a negative impact on the fatigue strength. As known, fatigue performance depends on the competition between beneficial factors and harmful factors, which are mainly affected by the following four factors: the degree of surface grain nanocrystallization, the size of introduced residual compressive stress, the size of near-surface microhardness, and weld toe repair. The measurement results acquired from the toe radius measurement method are shown in Fig. 11. Results show that the size of nanocrystals is small, the residual compressive stress and microhardness are large, but the UIT time is too long and the toe radius is small, which does not form a good arc transition. Compared with the undertreatment $r=2.46 \mathrm{~mm}$ and the better treatment $r=3.11 \mathrm{~mm}$, the treated $r=2.03 \mathrm{~mm}$ and the toe radius is small. It can be seen from the Fig. that the depth is large. To a certain extent, it appears to be a kind of macro defect with increased stress concentration. Moreover, the surface cracks produced during treatment make the material undergo premature failure and the fatigue performance becomes poor.

According to the existing data, the mathematical equation is fitted by Origin as follows:

For tandem MIG welded joints, the Equation between ultrasonic impact time $t$ and grain size $D$ is:

$$
\mathrm{D}=29.75891+7.6198 \& \mathrm{e}^{-\mathrm{t} / 4.59232}
$$

The Equation between fatigue strength $\Delta \sigma$ and ultrasonic impact time $t$ is as follows: 


$$
\Delta \sigma=7215.17079 \mathrm{D}^{-1.58903}
$$

The Equation between fatigue strength $\Delta \sigma$ and ultrasonic impact time $\mathrm{t}$ is as follows:

$$
\Delta \sigma=29.56+8.3 e^{-\frac{(t-15)^{2}}{54.47}}
$$

In Equation (2), the function equation has a minimum point, and the grain size of the tandem MIG welded joint is smaller than that of the tandem MIG welded joint under the same UIT time. In Equation (3), the fatigue strength of welded joint is larger than that of the tandem MIG welded joint under the same grain size. In Equation (4), there are maximum points in both functions and the fatigue strength of the tandem MIG welded joint is larger than that of the tandem MIG welded joint under the same UIT.

\section{Conclusions}

In this study, the tandem MIG welded joint of 7A52 aluminum alloy was subjected to UIT at different times. By testing the surface morphology, microstructure, and mechanical properties of the specimens with different treatment times, the UIT time that yielded a better performance was analyzed. The conclusions are as follows $\rrbracket$

1) When the ultrasonic impact time is $15 \mathrm{~min}$, the surface of the welded joint is smooth without obvious gully and the best morphology is achieved.

2) When the ultrasonic impact time is $5 \mathrm{~min}, 10 \mathrm{~min}$, and $15 \mathrm{~min}$, the better plastic deformation layer appears on the weld surface and the grain refinement is obvious.

3) Results show that the grain size decreases with the increase of ultrasonic impact time. The largest percentage of grain size reduction occurs when the UIT is $15 \mathrm{~min}$. Subsequently, the grain is crushed to saturation.

4) The surface microhardness of welded joint after ultrasonic impact increases with the increase of impact time. When the impact time increases from $2.5 \mathrm{~min}$ to $15 \mathrm{~min}$, the microhardness increases the most.

5) UIT will transform the residual stress from tensile stress to compressive stress. When the ultrasonic impact time is $15 \mathrm{~min}$, the average residual compressive stress of welded joints is the largest.

6) Compared with the original welding condition, the fatigue strength of the welded joints of 7A52 aluminum alloy is the highest when the ultrasonic impact time is 15 min with an increase rate of $32.33 \%$.

As revealed by the above results, the proper treatment of UIT was 15 minutes. UIT can improve the surface microhardness and fatigue strength of welded joint, which is suitable for practical engineering 
application.

\section{Declarations}

\section{Acknowledgments}

This research was supported by National Natural Science Foundation of China (51165026), (51765053) and Natural Science Foundation of Inner Mongolia Autonomous Region (2015MS9537).

Ethics approval: We are sure that the manuscript does not violate ethics approval.

Consent to participate: All authors agreed to participate.

Consent to Publish: All authors have read and agreed to the published version of the manuscript.

\section{Authors' contributions:}

Furong Chen: Conceptualization; validation; upervision; project administration; project administration; supervision, funding acquisition.

Yihang Yang: software; validation; formal analysis; data curation; writing-original draft preparation; writing-review and editing; visualization.

Nan Li: Conceptualization; methodology; validation; investigation; resources.

Funding: This research was supported by National Natural Science Foundation of China (51165026), (51765053) and Natural Science Foundation of Inner Mongolia Autonomous Region (2015MS9537).

Conflicts of interest/Competing interests: The authors declare no conflict of interest.

Availability of data and materials: The data presented in this study are available on request from the corresponding author.

Code availability: Not applicable.

\section{References}

1. Mordyuk B, Prokopenko G, Milman YV, lefimov M, Sameljuk A (2013) Enhanced fatigue durability of Al-6Mg alloy by applying ultrasonic impact peening: Effects of surface hardening and reinforcement with AlCuFe quasicrystalline particles. Mater Sci Eng A 563, 138-146. https://doi.org/10.1016/j.msea.2012.11.061

2. Chen C, Chen F, Zhang H (2018) Surface Nanocrystallization of 7A52 Aluminum Alloy Welded Joint by Aging and Ultrasonic Impact Compound Treatment. Rare Met Mater Eng 47, 2637-2641. https://doi.org/10.1016/S1875-5372(18)30201-7 
3. Hong H, Han Y, Yao Q, Tong J (2018) Microstructural Investigation of VPPA-GMAW Welded 7A52 Aluminum Alloys. J Mater Eng Perform 27, 5571-5580. https://doi.org/10.1007/s11665-018-3450-3

4. Hamed Zargari H, Ito K, Miwa T, Parchuri PK, Yamamoto H, Sharma A (2020) Metallurgical Characterization of Penetration Shape Change in Workpiece Vibration-Assisted Tandem-Pulsed Gas Metal Arc Welding. Materials 13, 3096. https://doi.org/10.3390/ma13143096

5. Ueyama T, Ohnawa T, Tanaka M, Nakata K (2005) Effects of torch configuration and welding current on weld bead formation in high speed tandem pulsed gas metal arc welding of steel sheets. Sci Technol Weld Joi 10, 750-759. https://doi.org/10.1179/174329305X68750

6. Castillo-Morales M, Berber-Solano TP, Salas-Zamarripa A. et al. (2020) Effectiveness of the ultrasonic impact treatment in the retardation of the fatigue crack growth for 2024-T3 Al alloy components. Int J Adv Manuf Technol 108, 157-165 . https://doi.org/10.1007/s00170-020-05064-9

7. Yu J, Gou G, Zhang L, Zhang W, Chen H, Yang YP (2016) Ultrasonic Impact Treatment to Improve Stress Corrosion Cracking Resistance of Welded Joints of Aluminum Alloy. J Mater Eng Perform 25, 3046-3056. https://doi.org/10.1007/s11665-016-2087-3

8. Cheng Z, Cao X, Xu X, Shen Q, Yu T, Jin J (2020) Effect of Ultrasonic Surface Impact on the Fatigue Properties of Ti3Zr2Sn3Mo25Nb. Materials 13, 2107. https://doi.org/10.3390/ma13092107

9. Nam YS, Jeong YI, Shin BC, Byun JH (2015) Enhancing surface layer properties of an aircraft aluminum alloy by shot peening using response surface methodology. Mater Des 83, 566-576. https://doi.org/10.1016/j.matdes.2015.06.065

10. Wang D, Hu D, Deng C, Wu S, Gao Z (2020) Effect of heat treatment combined with ultrasonic impact on fatigue property of Q345B steel welded joint. Trans China Weld. Inst 41, 6-11. https://doi:10.12073/j.hjxb.20191106003

11. Lago J, Trško L, Jambor M, Nový F, Bokůvka O, Mičian M, Pastorek F (2019) Fatigue Life Improvement of the High Strength Steel Welded Joints by Ultrasonic Impact Peening. Metals 9, 619. https://doi.org/10.3390/met9060619

12. Lesyk DA, Mordyuk BN, Martinez S, lefimov MO, Dzhemelinskyi VV, Lamikiz A (2020) Influence of combined laser heat treatment and ultrasonic impact treatment on microstructure and corrosion behavior of AISI 1045 steel. Surf Coat Technol 401, 126275.

https://doi.org/10.1016/j.surfcoat.2020.126275

13. He B, Deng H, Jiang M, Wei K, Li L (2018) Effect of ultrasonic impact treatment on the ultra high cycle fatigue properties of SMA490BW steel welded joints. Int J Adv Manuf Technol 96, 1571-1577. https://doi.org/10.1007/s00170-017-0608-3

14. Yuan K, Sumi Y (2016) Simulation of residual stress and fatigue strength of welded joints under the effects of ultrasonic impact treatment (UIT). Int J Fatigue 92, 321-332.

https://doi.org/10.1016/j.ijfatigue.2016.07.018

\section{Figures}




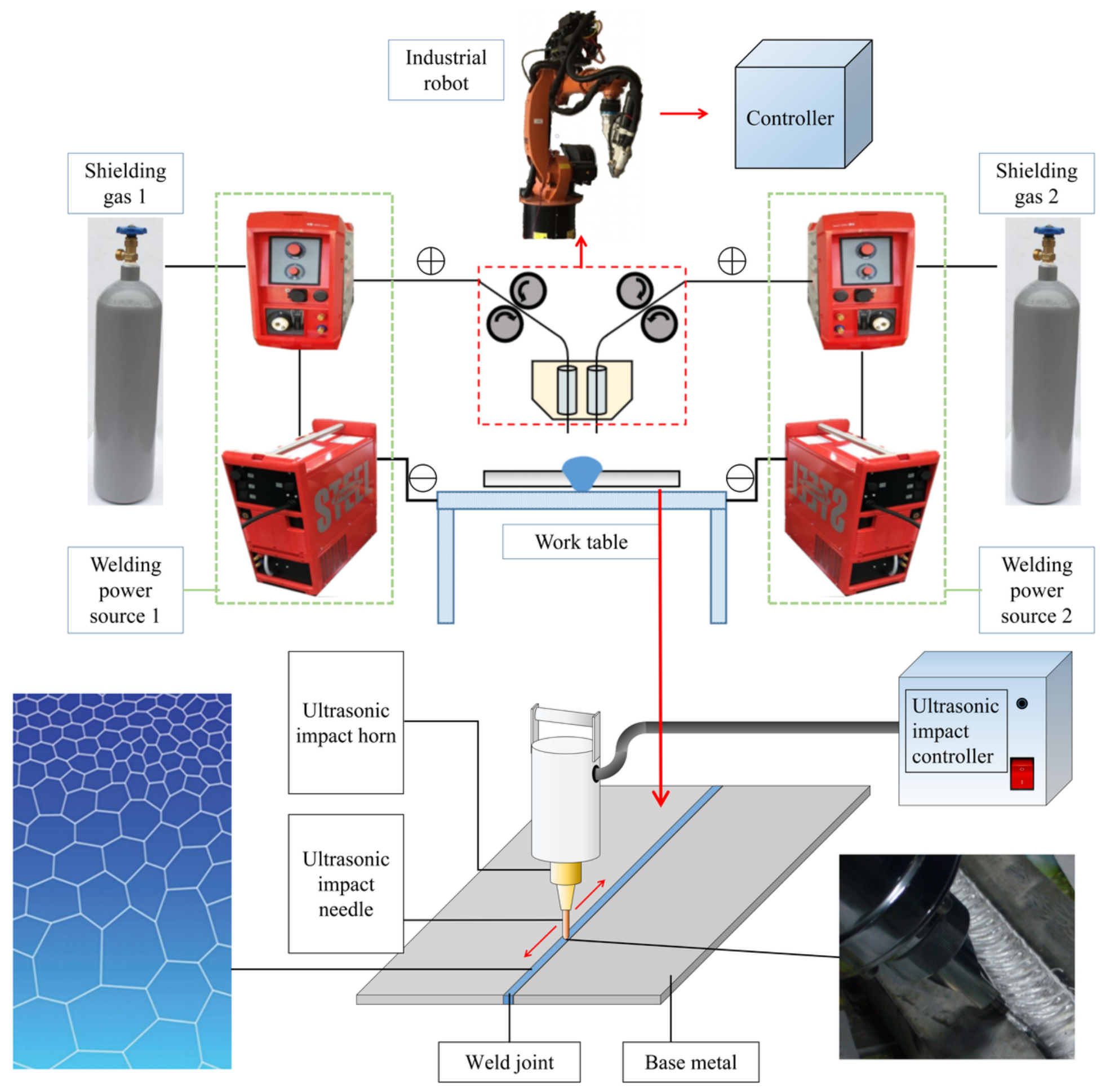

Figure 1

Schematic diagram of tandem MIG welding and UIT process. 


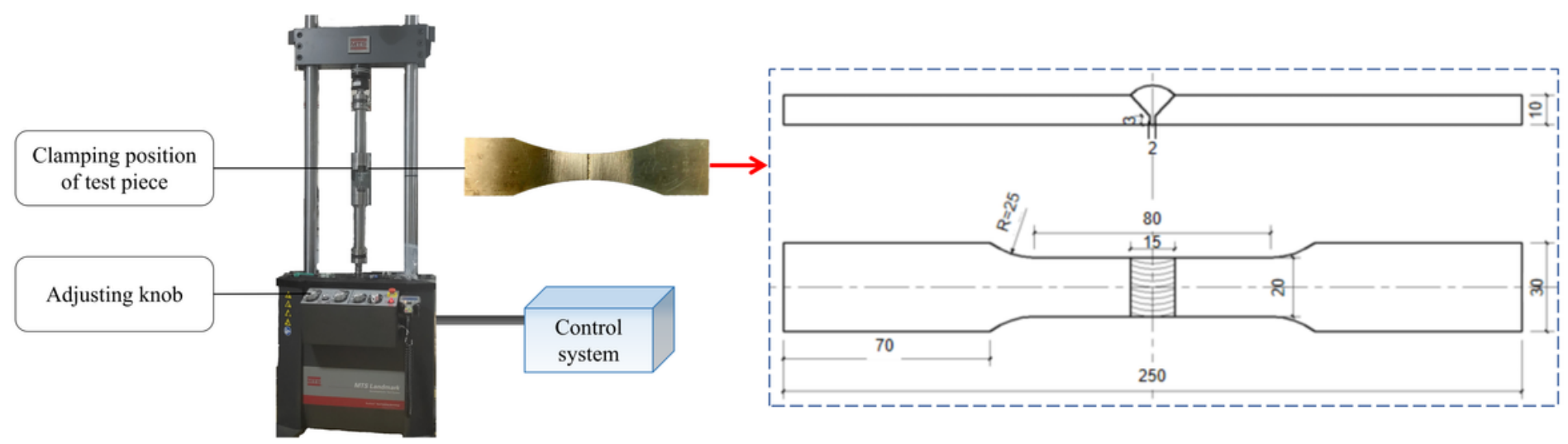

Figure 2

Schematic diagram of fatigue test.
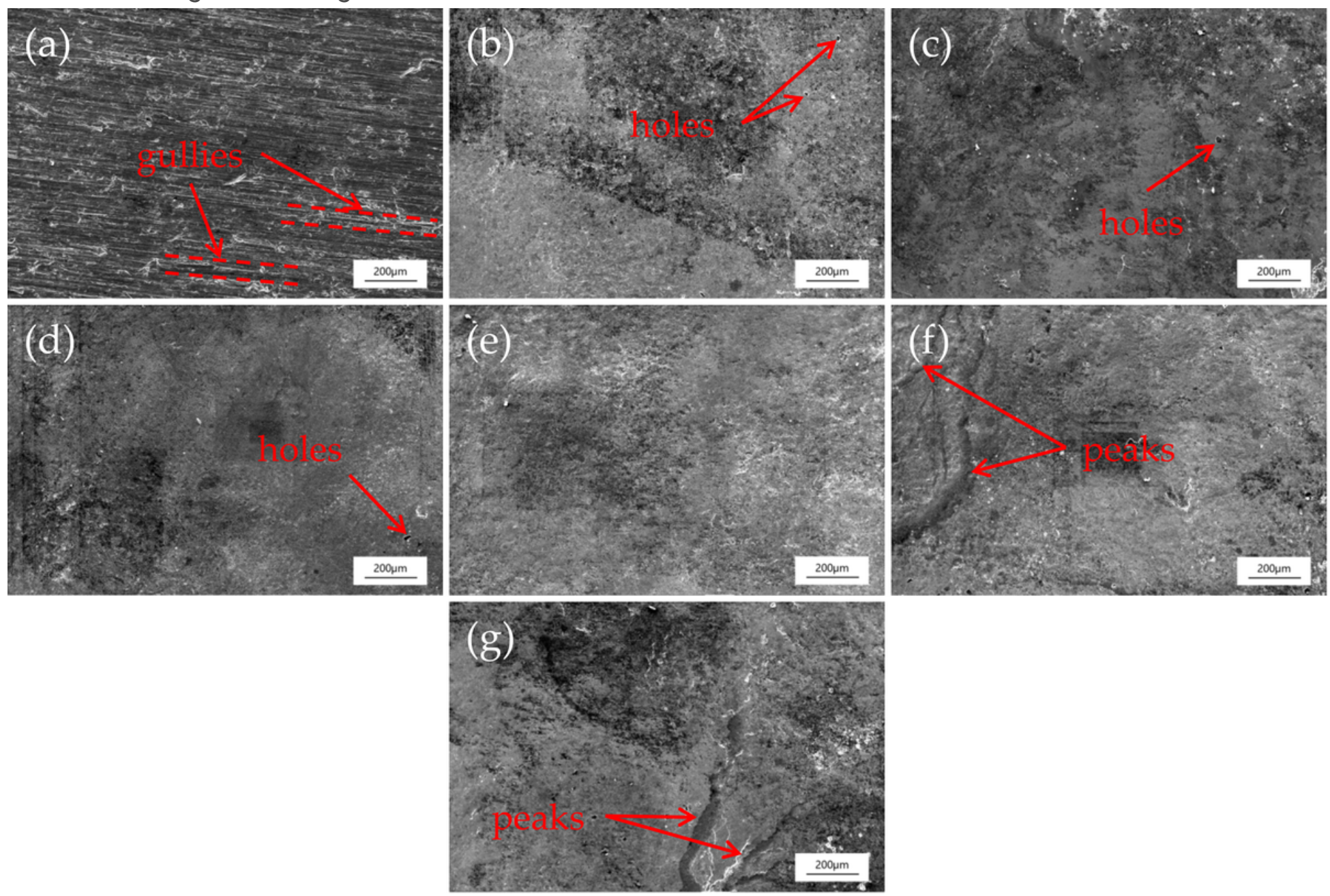

\section{Figure 3}

Surface morphology of tandem MIG welded joint at different ultrasonic impact times (a) untreated, (b) $2.5 \mathrm{~min},(\mathrm{c}) 5 \mathrm{~min},(\mathrm{~d}) 10 \mathrm{~min},(\mathrm{e}) 15 \mathrm{~min},(\mathrm{f}) 30 \mathrm{~min},(\mathrm{~g}) 75 \mathrm{~min}$. 


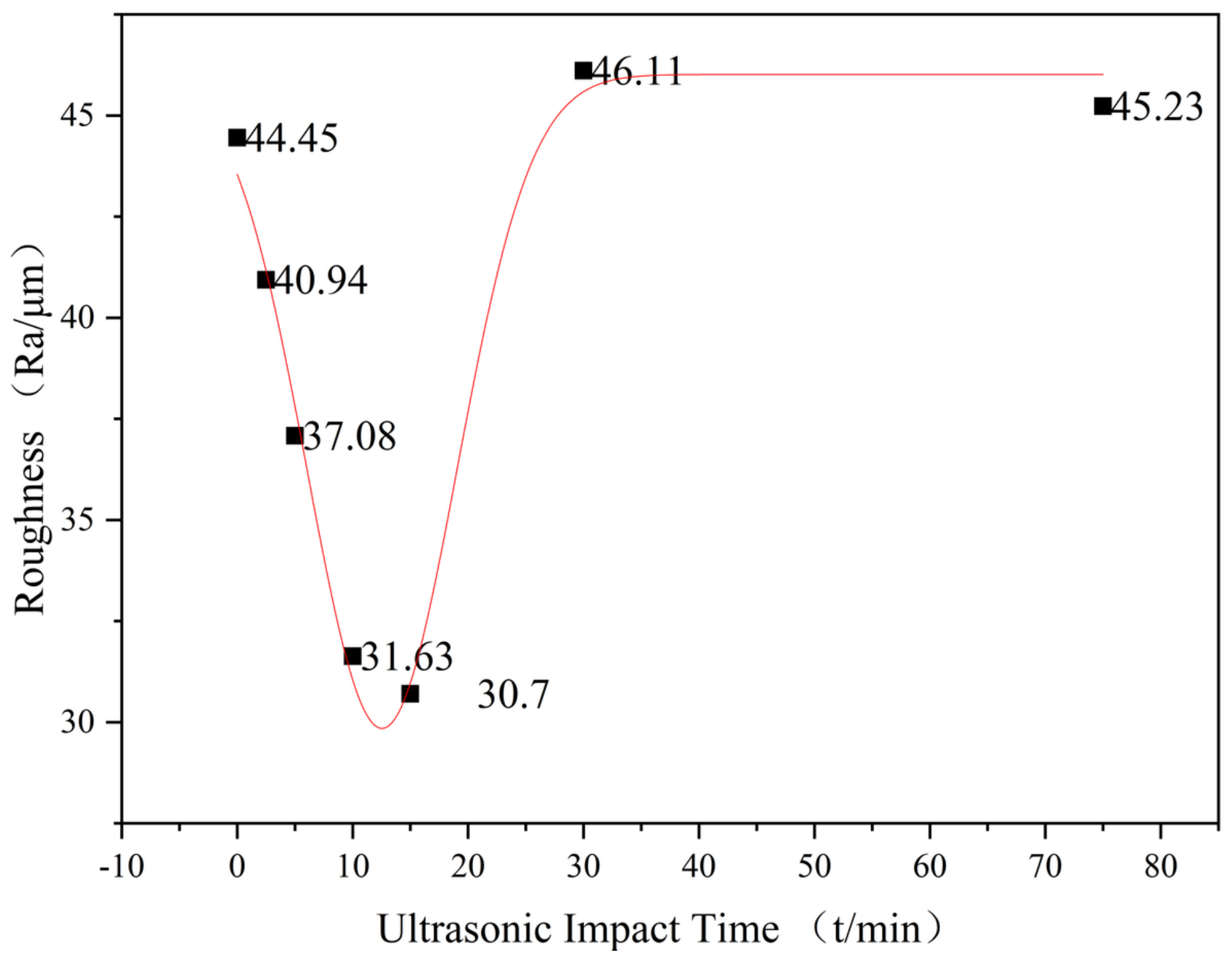

Figure 4

Surface roughness of tandem MIG welded joints treated by ultrasonic impact at different times. 

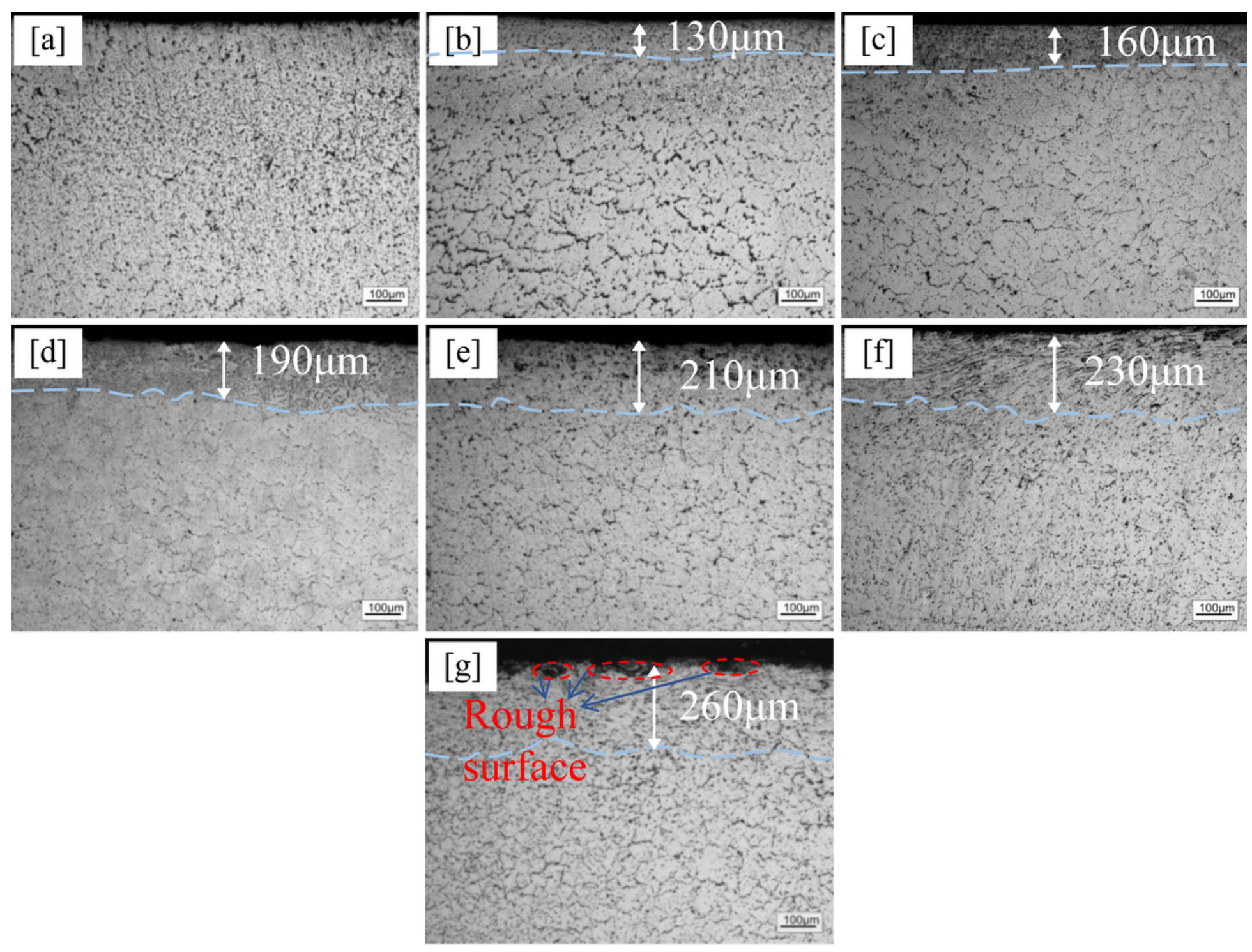

\section{Figure 5}

Surface microstructure of welds treated by ultrasound shock at different times. (a) untreated, (b) 2.5 min, (c) $5 \mathrm{~min},(\mathrm{~d}) 10 \mathrm{~min},(\mathrm{e}) 15 \mathrm{~min}$, (f) $30 \mathrm{~min},(\mathrm{~g}) 75 \mathrm{~min}$. 


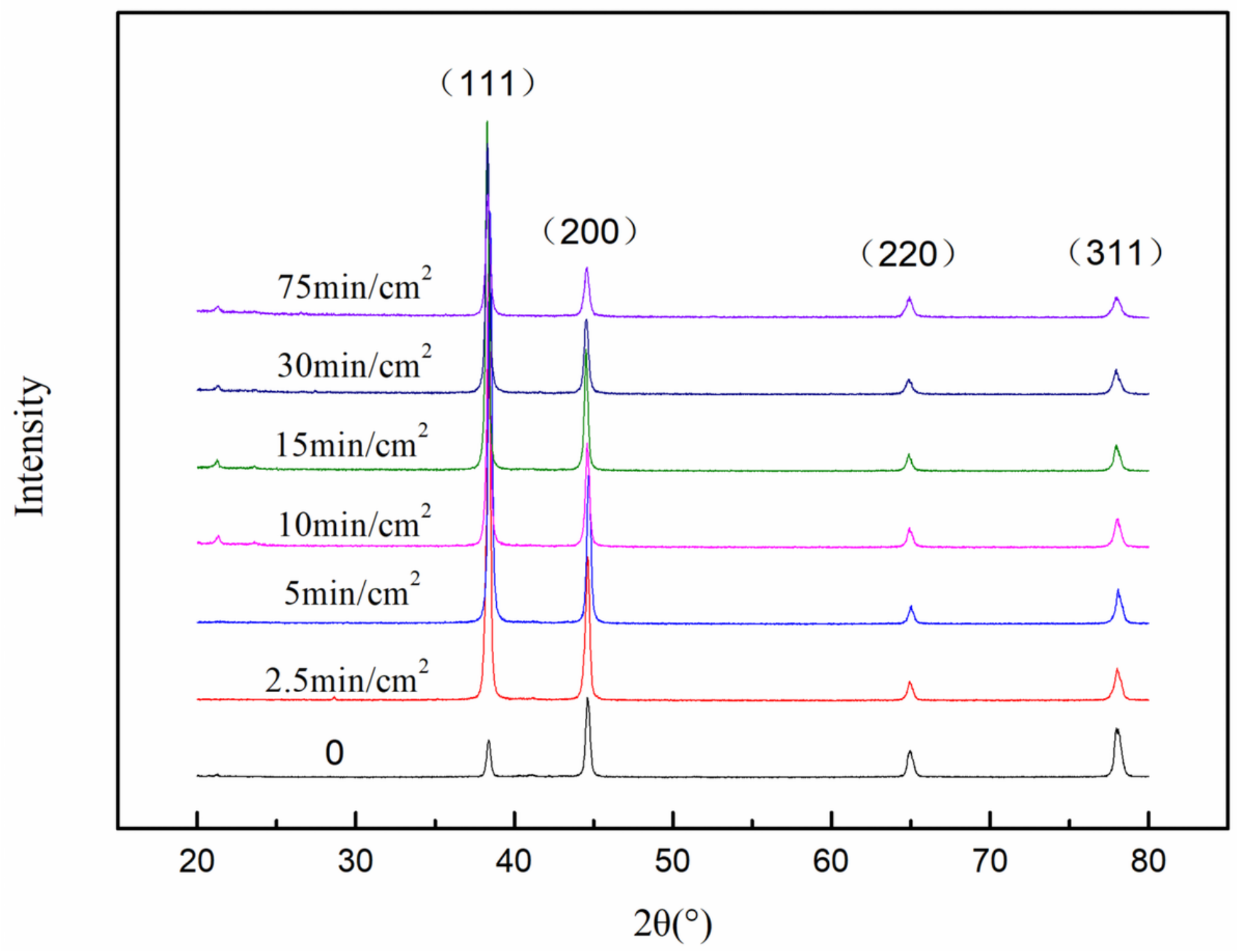

Figure 6

XRD diffraction pattern of joints at different UIT times. 


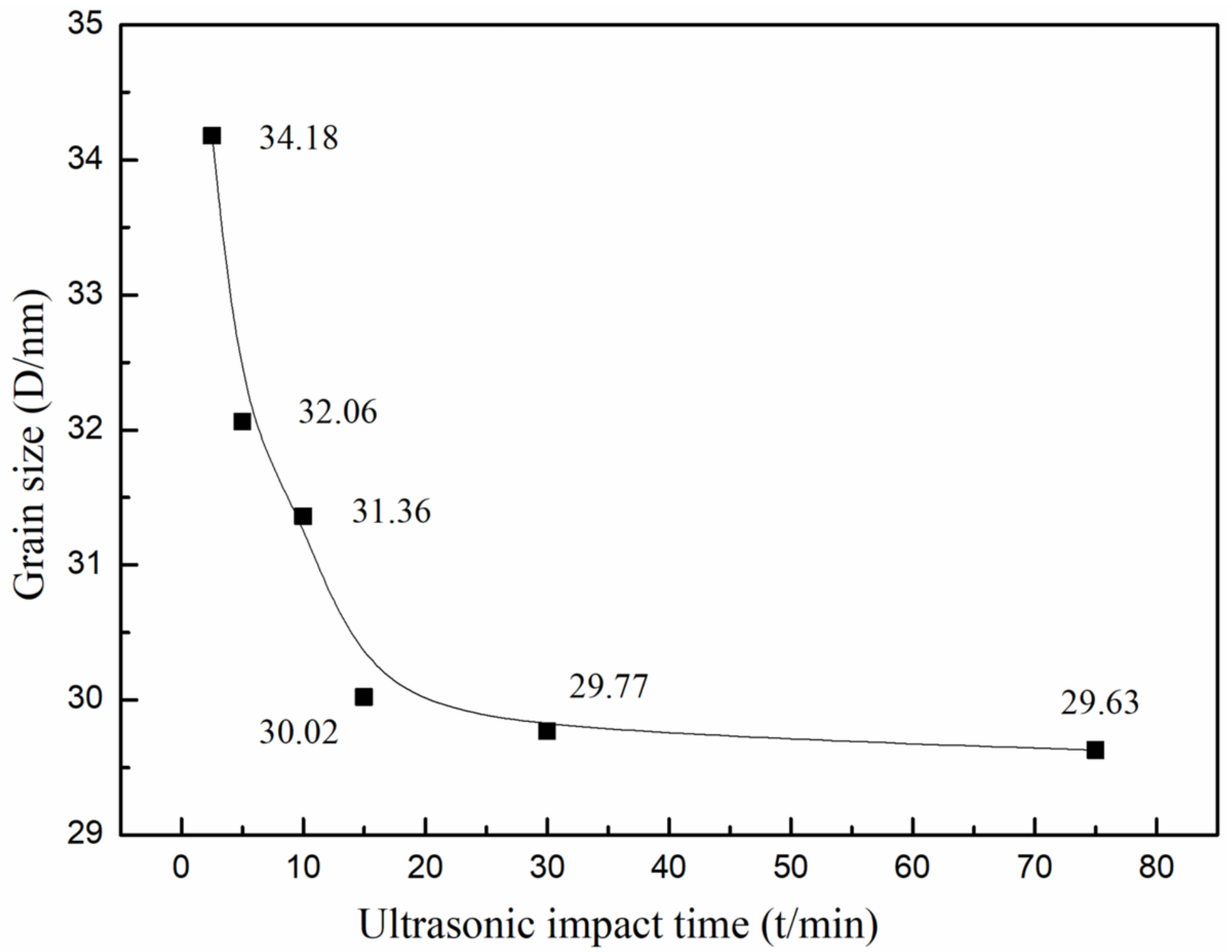

Figure 7

Grain size of UIT at different times. 


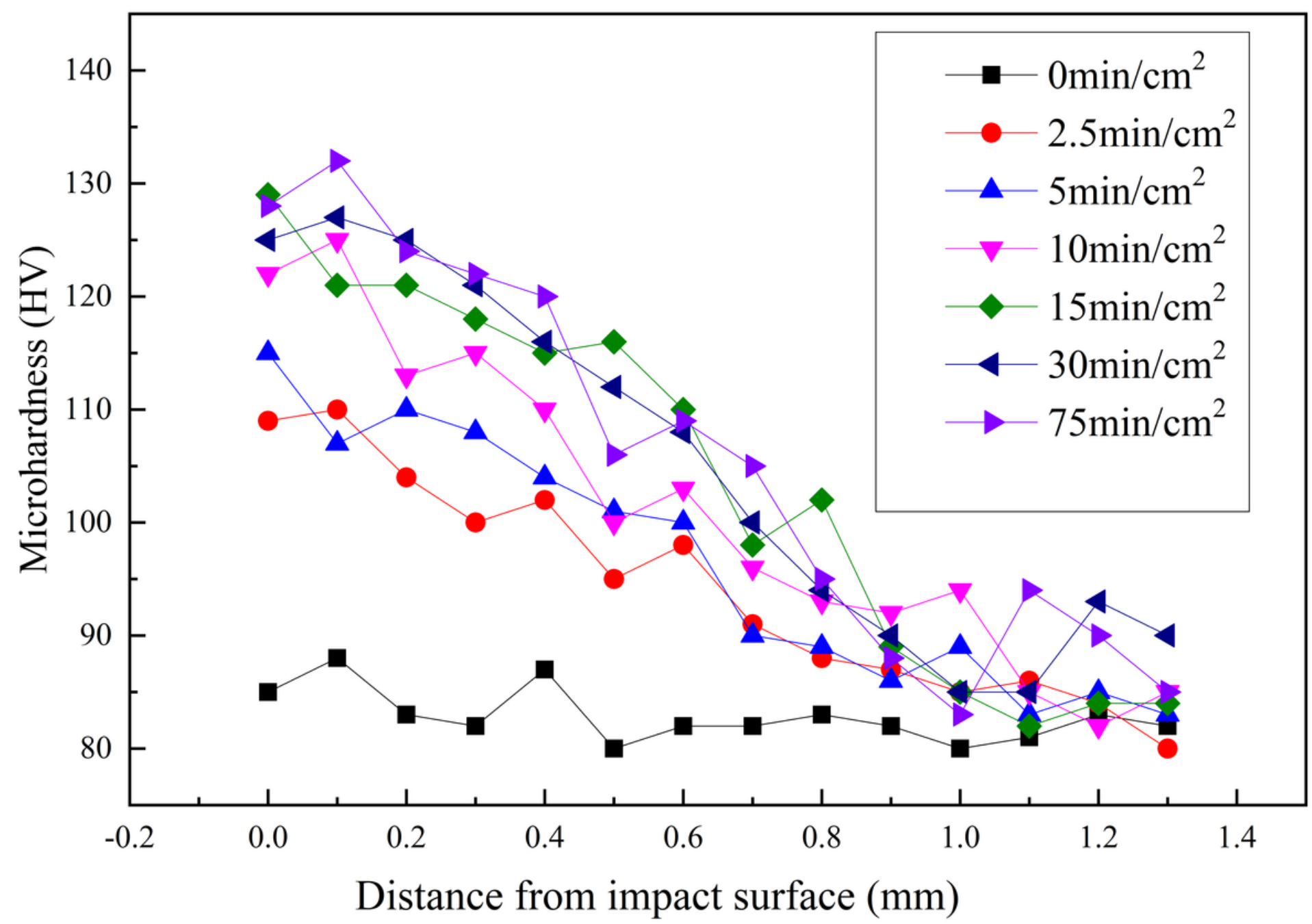

Figure 8

Microhardness change of weld area after UIT at different times.
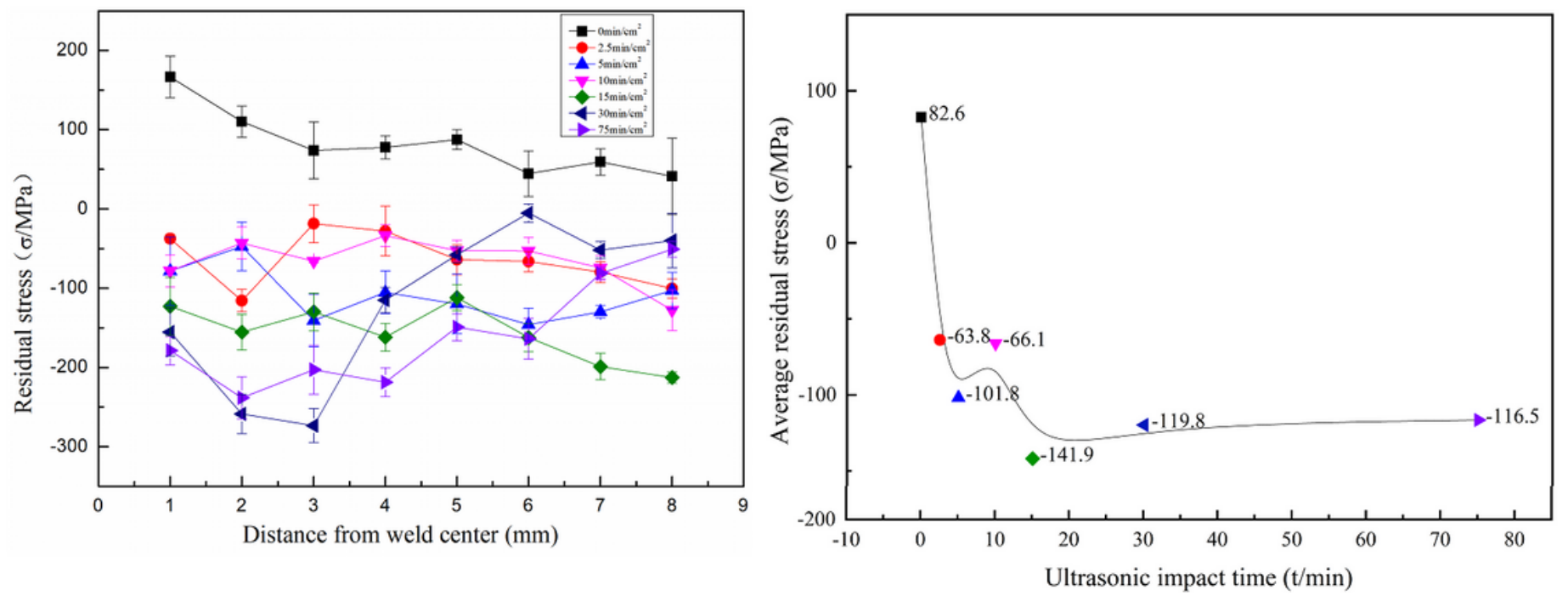

Figure 9 
Distribution of residual stress at different times of UIT. (a) Residual stress measurement results. (b) Average residual stress.

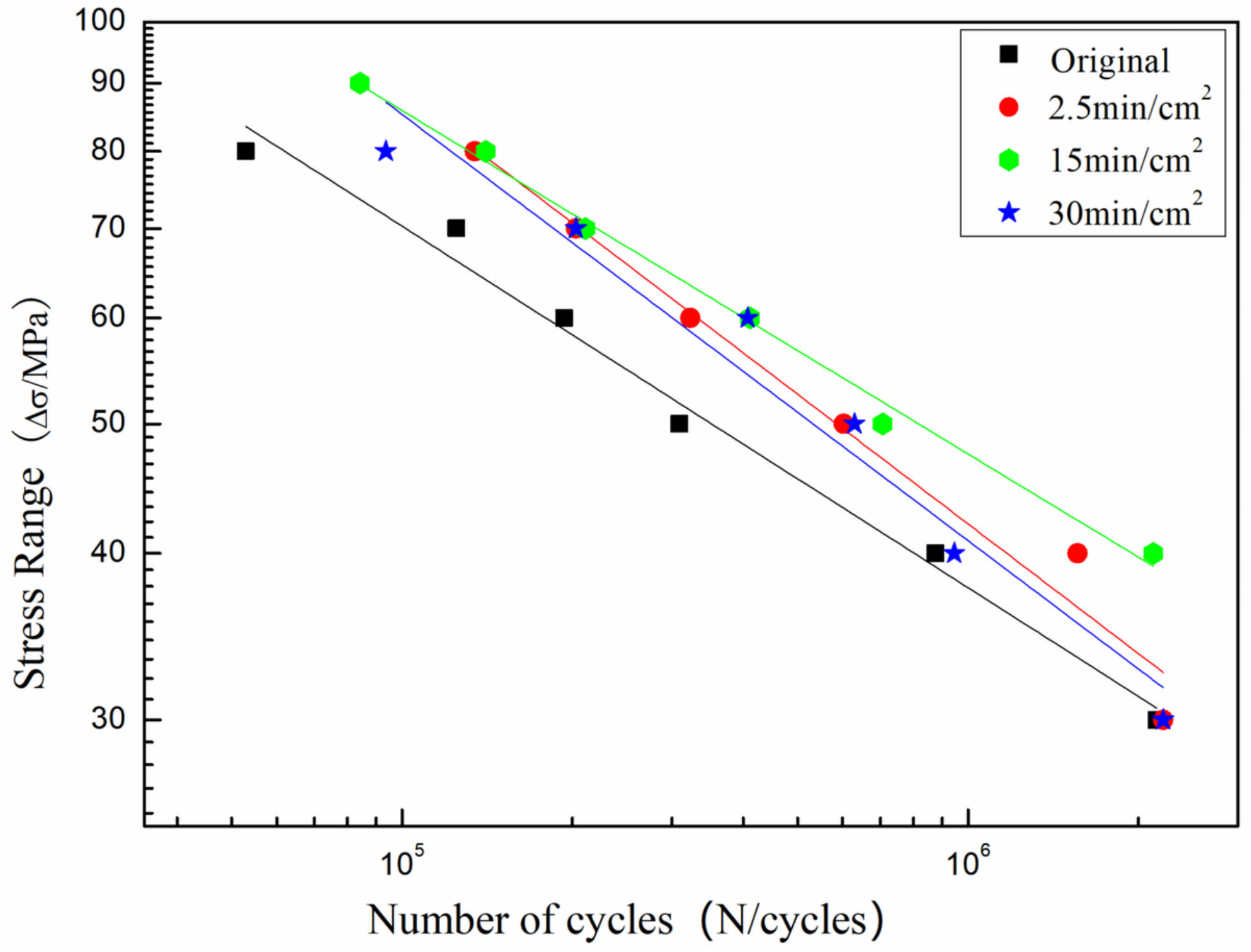

Figure 10

S-N curve $(r=0.1)$ of different times of UIT for welded joint. 


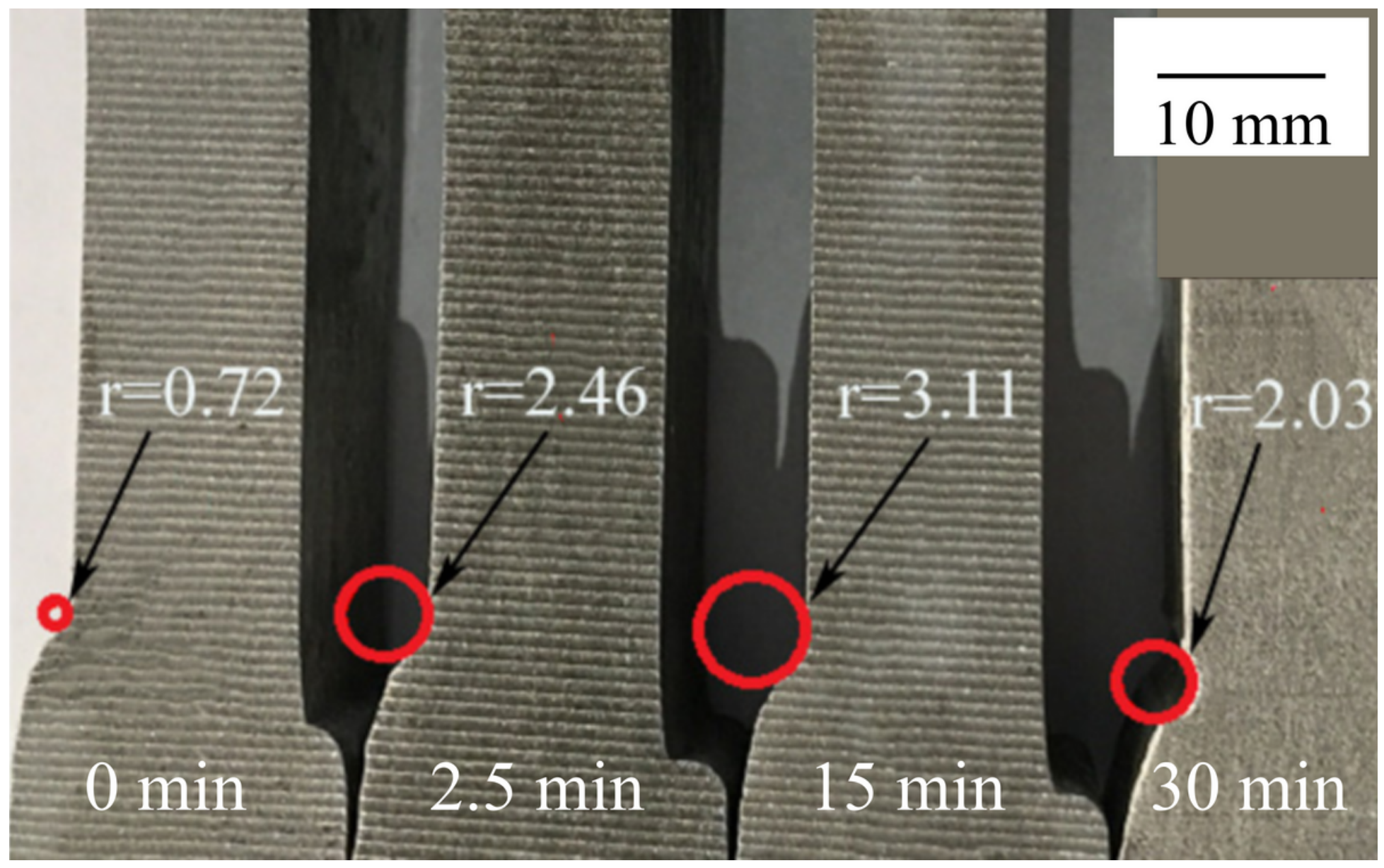

Figure 11

Geometric dimension of weld toe area of welded joint $(\mathrm{mm})$ 